\title{
Facility Disruptions in a Closed-loop Supply Chain Featuring Warranty Policy and Quality-based Segmentation of Returns
}

\author{
Yasin Mansouri \\ Ph. D Candidate of Industrial Engineering \\ Department of Industrial Engineering \\ College of Engineering, Shahed University, Tehran, Iran \\ Address: Shahed University, Persian Gulf Expressway, Tehran, Iran, Postal Code: 3319118651 \\ Email: yasinm1370@yahoo.com, Mobile: +989012549864
}

\author{
* Rashed Sahraeian \\ Professor of Industrial Engineering \\ Department of Industrial Engineering
}

College of Engineering, Shahed University, Tehran, Iran

Address: Shahed University, Persian Gulf Expressway, Tehran, Iran, Postal Code: 3319118651

Corresponding author: Sahraeian@ shahed.ac.ir, Mobile: +989122145489 


\title{
Facility Disruptions in a Closed-loop Supply Chain Featuring
}

\section{Warranty Policy and Quality-based Segmentation of Returns}

\begin{abstract}
This paper focuses on a closed-loop supply chain that deals with disruptions in the distribution centers, and optimizes the network in two dimensions of sustainability: economic and environmental. Avenues for cost minimization are designed for the customer by adding the warranty periods, the reworking options, and the incentives for returning the used items. Nondominated solutions via the Reservation Level-driven Tchebycheff procedure are found by appropriate choice of facility establishment and suitable allocation links considering the disruption in the distribution centers. The concept of primary and supporting allocations are introduced to address the disruptions and ensure an uninterrupted flow of service. Environmentally, the model adopts a zero-waste strategy by embedding various return-segmentation policies and a secondary chain. The backward flow depends on the customers' choice of reworking, the validity of the warranty contract, and the quality of the returns. The test results indicate that the manufacturing and distribution centers prefer returns with medium-range quality, while due to the incentives offered for the recyclable items, the customers benefit the most from returning the items with the lowest quality. The tests on probability of disruptions indicate that establishing a minimum number of the manufacturing and/or distribution sites without disruption leads to better overall performance.
\end{abstract}

\section{Keywords:}

Closed-loop supply chain networks; disruption; facility failure; return quality management; mixed integer programming; reservation level-driven Tchebycheff procedure 


\section{Introduction}

A closed-loop supply chain network $(C L S C N)$ imitates the workings of a dynamic, complex, and large-scale system with forward and reverse flows. In a CLSCN, various decisions are necessary to ensure an acceptable outcome, and the more complex a network, the greater the uncertainty level of the decision-making [1]. The rationale of handling uncertainties in a CLSCN revolves around the optimization of one or more of the sustainability dimensions; economic, social, and environmental aspects [2]. In a CLSCN, uncertain scenarios can be typically classified into two main categories [3]:

a) Uncertainties are linked to strategic decision-making, e.g., finding the optimum production capacity, placement of facilities, customer allocation, supplier selection, node-to-node links in the network, segmentation policies in the backward flow, and transportation among different levels of the $S C$.

b) Uncertainties are taken into account while calculating the reliability or robustness of the network to handle the imprecision or inexactness of information (e.g., due to dynamism and fluctuation in demands, capacities, and timings), potential vulnerability and risks (e.g., due to globalization or leanness), and disruptions (e.g., due to random incidents, natural disasters, political tensions, epidemic outbreaks, and terrorist attacks).

The present paper relates to both categories in which, $(a)$ the establishment of the facilities and the customer allocation are uncertain; (b) disruptions may occur in distribution centers (DCs), hindering the service to the customers; and $(c)$ the flow of the returned items in the backward chain depends on the warranty agreement and the quality-based segmentation policies. The novel contributions of this paper are listed as follows: 
1. Instead of the usual approach of maximizing the chain profit prior to sending out the product and excluding the customer benefits, the proposed CLSCN recognizes the customer as an integral part of the chain and includes the customer's profit in the optimization model.

2. As a proactive approach, in order to increase the reliability of the CLSCN, the model determines the location of the DCs and their corresponding customer allocation, both for the primary and supporting DCs, simultaneously. Hence, upon the occurrence of disruptions, two sets of allocation decisions are available to the decision-maker. Moreover, the supporting allocation is always directed to the $D C s$ without disruptions to ensure the constant availability of service.

3. In the backward flow, the returns are handled based on the customers' preference, warranty validation and the quality of used items as follows:

a. If the warranty period is still valid, the product is first collected by the $D C$ s, and then sent back to the manufacturer for remanufacturing, and finally returned to the customer free of charge.

b. If the warranty period is ended, three scenarios may occur:

i. The damage to the item is minimal, so the customer may prefer to personally take the product to a nearby shop for a quick repair, forgoing the time and cost of returning the product to the chain (i.e., reworking by the customer).

ii. The product is fairly damaged; thus, the customer returns the product to the $D C$ s for repair.

iii. The returned product by the customer (for an incentive) is unusable in its current form, so it is sent out through the $D C$ s to a secondary chain to be salvaged for parts. 
The idea is to maximize the overall profit while maintaining the sustainability and reliability of the chain by creating a zero-waste network, which is functional even in the face of disruptions.

The literature related to the paper has been classified into three parts: papers related to the $C L S C$ focusing on the sustainability of the chain, research regarding the facility location in the $C L S C$, and the articles featuring $C L S C$ with the possibility of disruption across facilities.

\subsection{Sustainability in the CLSCN}

In the recent decades, extensive research has been carried out on the CLSC in response to the increasing awareness regarding the environmental issues in order to preserve the finite natural sources, increase profit, and improve the social welfare. For instance, [4] conduct a comprehensive research on a $C L S C$, which uses a secondary supply chain as a recycling outlet for the used items. The additional chain also creates a passive income by selling the recycled items, thus increasing the overall profit of the chain.

It was addressed the environmental issues in a bi-level $C L S C N$ including the manufacturers and the retailers [5]. In the paper, three sustainability factors regarding the environment are considered in $a$ ) the materials used in the (re)production activities, $b$ ) the greenhouse gases emissions resulted from the production and transportation activities, and c) the materials used for reproduction (recycling).

Maiti \& Giri use the game theory to review the recovery policies [6]. Their division policy is based on a pre-determined minimum quality, calculated from the cost of reconstruction. Thus, if the returned product has a quality higher than the minimum required quality, it will be sent for reconstruction, otherwise, it will be sold in the secondary market. 
$\mathrm{Xu}$ and others propose a CLSC to tackle the issue of carbon emissions [7]. Their CLSC has extended recovery options, providing independent facilities for collecting, sorting/testing, reconstruction, repair, redistribution, recycling, and disposal of the used products. However, similar to the previous research, the amounts of products entering these facilities are partially predetermined.

Masoudipour and others propose a $C L S C N$ in the textile industry, where the returned products are collected through Distribution/Collection centers (DCs), and divided according to their quality [8]. In the reverse chain, the returned products are divided into three categories: products that require simple repairing, products that have to be returned to the factory for reproduction operations, and finally recyclable products, which should be sent to the secondary chain. Moreover, a bi-objective, mixed integer programming model is used to maximize the profits of the manufacturers and distribution centers. Similar to their study, in our present model, the policy of classification and separation of the returned products is considered based on the product quality, and the modeling is based on maximizing the profitability of the entire supply chain.

Zhen present an integrated landscape for the development of a green and sustainable ring of supply chain network under uncertain demands [9]. A two-objective optimization model is proposed to reduce the $\mathrm{CO} 2$ emissions and the total operating costs. The returned products from the customers are considered repairable.

\subsection{Facility location in CLSC}

Yi designed a retail-oriented $C L S C$ network to reproduce the end-of-life construction machinery, while investigating the location of the facilities [10]. The designed network is tackled by a geneticalgorithm-based exploration method. 
Ahmadzadeh \& Vahdani integrated decision-making strategies into the location, inventory, and pricing of a closed-loop network, considering the customer demands [11]. Their solution approach involves two encryption and decryption methods to solve the $C L S C$.

Mirmohammadi and Sahraeian designed the distribution network including determining the number and location of the facilities, allocating the customers in the network, and determining the transport of different goods from different origins to different destinations in the distribution network [12]. Returned products in the reverse chain were divided into four categories according to their quality: repairable, recyclable, disposable, and renewable (to be sold in the secondary chain).

Yu and Solvang develop a new multi-objective, fuzzy-random mathematical model to design a stable $C L S C$ network [13]. This model is developed to make a balance in the trade-off between the cost efficiency and environmental performance in different types of uncertainty. The environmental performance of the network is measured by considering the amount of carbon emissions. Decisions are also made to locate the facilities.

Govindan and others propose a combined approach including the fuzzy analysis of networking process and mixed integer linear multi-objective programming models [14]. Furthermore, the selection of a circular source and allocation of orders in the CLSC led to the development of several products with regard to the issue of green routing and usage of the heterogeneous vehicles. Consequently, a mathematical model is developed for a routing-inventory-location problem to minimize the cost and the scarcity in an uncertain environment.

\subsection{Probability of disruption in CLSC}


In the related literature, the term disruption is mostly used to indicate random uncertainty; basically, any happening out of the norm, which negatively impacts the chain.

For instance, researchers study an environmentally sustainable $C L S C N$, where demand disruptions occur at the supplier's level, and the resultant effect reverberates throughout the chain, impacting the retailer's action, and the delivery times [15]. The uncertain variables of the chain are considered as fuzzy numbers and tackled by the combination of Karush-Kuhn-Tucker (KKT) conditions and possibility theory.

Similarly, Diabat and others design a reliable $S C$ network with perishable products considering disruptions [16]. Disruption, in this case, is defined as disaster scenarios; which upon their occurrence, the proposed model endeavors to minimize the time and cost of the network by utilizing the Lagrangian relaxation and $\varepsilon$-constraint approaches.

Moreover, it was studied the effect of production disruption in an economic and environmentally sustainable $S C$ [17]. From the economic dimension, their three-echelon, Stackelberg game model maximizes the profit by determining the best pricing, inventory, and maintenance strategies. As for the environmental dimension, the aforementioned model also factors in the effect of carbon dioxide emission on the $S C$ network.

Also, Tong et al. focus on a sustainable CLSC minimizing the cost related to supply disruption and carbon tax [18]. The problem is tackled by metaheuristics, and the effects of different policies pertaining to the uncertain parameters on the optimal production and recycling strategies are investigated.

The study by Darom et al. is similar to the present paper since a predictive approach is defined in the $S C$ to counter the potential supply disruptions [19]. They use the concept of safety stock in a 
two-level, manufacturer-retailer chain to lower the disruption cost, and the carbon emission during the recovery mode.

Additionally, Shen focuses on a sustainable $S C$ considering the environmental impact of carbon dioxide emissions, and the social benefits of increasing employment opportunities [20]. The demand, cost, and capacity in this problem are uncertain, and hence the model is solved via the chance-constrained method.

Similarly, Mohammadi utilizes chance-constrained programming to tackle the problem of supplier selection with uncertain demands in a hazardous material $S C$ network [21].

Furthermore, it was minimized the total cost in a reliable $S C$ considering the demand uncertainty and facility disruptions [3]. The problem is formulated as a stochastic mixed-integer model and solved via the $L$-shaped decomposition method.

Based on the reviewed literature, it is apparent that the choice of the solution approach mainly depends on the specifications of the problem and the nature of the uncertainty. The review paper by [1] states that hybrid simulation-optimization methods are the most common way of optimizing uncertain $S C$ networks. The simulation side handles the uncertainty, while the optimization side achieves (near) optimal solutions. Discrete-event simulation and mixed-integer linear programming are mentioned as the two of the most used approaches of simulation and optimization methods, respectively.

The present study utilizes discrete-event scenarios and optimization modelling, in which based on the probability of disruption, the network either functions with the primary $D C$ (with disruption), or switches to a supporting $D C$ (without disruption) to ensure a reliable chain. The optimization model also factors in the best placement of the facilities, as well as, the forward and backward 
routings of the products via an interactive multi-objective decision-making technique known as the Reservation Level-driven Tchebycheff Procedure (RLTP).

The rest of this paper is organized as follows. Section 2 formulates the proposed $C L S C N$ as a mixed-integer model. Section 3 presents the proposed solution approach for the multi-objective model. Section 4 investigates the applicability and suitability of the solution approach on the model via a numerical example. Section 5 examines the relationships between the quality of returns and the probability of disruptions on the objective values. Finally, the managerial insights and conclusion are given in sections 6 and 7, respectively, and the promising research areas on the subject is suggested.

\section{Methodology}

The proposed CLSCN in the current paper is based on the model by Masoudipour [8], and the interested reader is referred to the corresponding paper for more details. The improved version of the model is depicted in Figure 1, and can be explained as follows:

- The forward flow consists of three stages: the manufacturing facilities, the DCs with (out) the possibility of disruptions, and the customers. The optimization model decides on facility establishment for the manufacturing and the distribution centers. Two types of allocations are calculated per customer; primary and supporting. Primary allocations can be directed at $D C s$ with or without disruptions. Supporting allocations, however, are only assigned to $D C s$ without disruptions to ensure a resilient structure. It should be noted that disruption is seen as a feature for the $D C \mathrm{~s}$, and ergo, a $D C$ can be established in a way that it may be unavailable at times (with disruption), or so fully equipped that it is always available (without disruptions). Since establishing the latter costs more than the former, the 
model balances out this choice by weighing the benefits of reducing establishment costs versus a constant flow of service.

- In the backward flow, the customers have the option of reworking the product themselves without shipping it back to the chain to save time and/or cost of a return process. Otherwise, they can send the product back to the $D C$ s. Once the $D C$ s collect the products, the warranty validation is checked. If the damage is covered under a valid warranty, the product is sent to the manufacturer to be fixed, and the remanufactured product is sent back to the customer. If the warranty is void, but the quality of the item meets the repairing specifications, then the $D C$ undertakes the repairing of the used item, and the cost of the process is inflicted upon the customer. If the product is beyond salvation, the $D C$ s buy back the product from the customers so as to avoid environmental violations, and sell it out as raw material to a secondary chain.

- An example of such a $C L S C N$ can be found in the supplying process of spare parts for the plants and machines across various industries (e.g., automotive spare parts, excavation, farming or earthworks machinery parts, hot-cast mechanical components and molds, and the machinery parts involved in textile, pneumatic, electromechanical, electronic, healthcare and medical industries). These parts often have extended warranty coverage, and the manufacturers encourage the customers to return the end-of-life products, either to avoid environmental violations/fines or to sell the recyclable returns (mostly consist of metal or plastic) to another chain. The quality measure of returns differs across various industries, and mainly includes the component's efficiency, compressive strength, wear rate, and depreciation [22]. 
The assumptions, notation and the mixed-integer mathematical formulation of the proposed CLSCN are explained as follows.

\subsection{Assumptions}

- The chain considers multiple types of products.

- The demands are fixed and known.

- The disruptions occur with a known probability, and the failure of a $D C$ does not impact the operation of other $D C$ s.

- The $D C$ s charge the customer for repairing a product without a warranty.

- A collecting fee is inflicted on the manufacturer, payable to the $D C$ s, for every returned product covered by a warranty.

- The profit gained by the customer from reworking the product himself or through routine maintenance (instead of returning it to the chain) is calculated by the difference between the final value of the reworked item and the cost of reworking it.

- A fixed price is imposed on the chain for opening a manufacturing or distribution facility.

- The cost of remanufacturing an item is considered lower than the manufacturing cost, and the sale price to the $D C$ s (i.e., $p s_{p a} \leq C_{p a} \leq p f_{p a} ; \forall p \in P, \mathrm{a} \in A$ ).

- For simplicity, the warranty validation is embedded in the model as a stage of quality check. In other words, if the damage to the product is covered by the warranty, the quality of the returned product is higher than the minimum quality required for remanufacturing (i.e., $q_{j a} \geq \operatorname{qrem}_{a} ; \forall j \in J, a \in A$ ). 
- The items returned to the $D C$ s undergo a primary quality-check, and are sorted based on a predefined segmentation policy to three categories of remanufacturing, repairing or recycling.

- The repair price of the products for the customers is assumed higher than the repair cost inflicted on the $D C$ s (i.e., $g a_{i a} \geq$ prep $_{i a} ; \forall i \in I, a \in A$ ).

- A fixed cost is inflicted on the $D C$ s for shipping the recyclable products to a secondary chain. To ensure profit, the cost is assumed lower than the sale price of such items to the secondary market (i.e., $g c_{i a} \geq p n s c_{i a} ; \forall i \in I, a \in A$ ).

- If an item is categorized as recyclable after the quality inspection, the $D C$ s buy back the item from the customer for half of its original price.

- Transportation costs are considered for shipping the cargos from the manufacturers to $D C$ s, and from the $D C$ s to the customers in the forward flow, as well as, transferring from the customers back to the $D C$ s in the reverse flow.

\subsection{Notation}

\section{Sets and Parameters}

$P ;(p \in P) \quad$ Set of candidate locations for opening a manufacturing facility

$I ;(i \in I) \quad$ Set of candidate locations for opening a $D C$

$\boldsymbol{J} ;(j \in J) \quad$ Set of fixed locations for the customer markets

$A ;(a \in A) \quad$ Set of different types of products

$\mathrm{Co}_{p} \quad$ Fixed cost of establishing the $p^{\text {th }}$ manufacturing facility

$f_{i}^{U} \quad$ Fixed cost of establishing the $i^{\text {th }} D C$ with disruption 


\begin{tabular}{|c|c|}
\hline$f_{i}^{R}$ & Fixed cost of establishing the $i^{\text {th }} D C$ without disruption \\
\hline$C_{p a}$ & The cost of producing $a^{\text {th }}$ product by the $p^{\text {th }}$ manufacturer \\
\hline$p f_{p a}$ & The sales price of the $a^{\text {th }}$ product by the $p^{\text {th }}$ manufacturer to the $D C$ s \\
\hline$p s_{p a}$ & The cost of remanufacturing the $a^{\text {th }}$ product by the $p^{\text {th }}$ manufacturer \\
\hline$p d f_{j a}$ & The price of $a^{\text {th }}$ original product sold by a $D C$ to the $j^{\text {th }}$ customer market \\
\hline$D_{j a}$ & The demand for the $a^{\text {th }}$ product from the $j^{\text {th }}$ customer market \\
\hline$\alpha_{j a}$ & The return rate of the $a^{\text {th }}$ product from the $j^{\text {th }}$ customer market to the $D C$ s \\
\hline$\beta_{j a}$ & The rework rate of the $a^{\text {th }}$ product carried out by the $j^{\text {th }}$ customer \\
\hline qrep $_{a}$ & The minimum quality required for repairing the $a^{\text {th }}$ type of product \\
\hline qrem $_{a}$ & The minimum quality required for remanufacturing the $a^{\text {th }}$ type of product \\
\hline$q_{j a}$ & The quality of the $a^{\text {th }}$ product returned by the $j^{\text {th }}$ customer \\
\hline prep $_{i a}$ & The repair cost of the $a^{t h}$ product by the $i^{\text {th }} D C$ (inflicted on the $D C$ ) \\
\hline $\operatorname{pnsc}_{i a}$ & The cost of sending the $a^{\text {th }}$ product through the $i^{\text {th }} D C$ to the secondary chain \\
\hline$g a_{i a}$ & The repair price of the $a^{\text {th }}$ product by the $i^{t h} D C$ (inflicted on the customer) \\
\hline$g b_{i p a}$ & $\begin{array}{l}\text { The sale price of the } a^{\text {th }} \text { product sent from the } i^{\text {th }} D C \text { to the } p^{\text {th }} \text { manufacturer for } \\
\text { remanufacturing }\end{array}$ \\
\hline$g c_{i a}$ & The cost of selling the $a^{\text {th }}$ product to the secondary chain by the $i^{\text {th }} D C$ \\
\hline
\end{tabular}


$e f_{j a}$

$h_{\text {pia }}$

$h_{i j a}^{P}$

$h_{i j a}^{B}$

$h e_{j i a}^{P}$

$h e_{j i a}^{B}$

M

$1-p o_{i} \quad$ Probability of disruption in the $i^{\text {th }} D C$

The cost of reworking the $a^{\text {th }}$ product by the $j^{\text {th }}$ customer

The cost of transporting the $a^{\text {th }}$ product from the $p^{\text {th }}$ manufacturer to the $i^{\text {th }} D C$

The cost of transporting the $a^{\text {th }}$ product from the $i^{\text {th }}$ primary $D C$ to the $j^{\text {th }}$ customer

The cost of transporting the $a^{\text {th }}$ product from the $i^{\text {th }}$ supporting $D C$ to the $j^{\text {th }}$ customer

The cost of transporting the $a^{\text {th }}$ product from the $j^{\text {th }}$ customer to the $i^{\text {th }}$ primary $D C$

The cost of transporting the $a^{\text {th }}$ product from the $j^{\text {th }}$ customer to the $i^{\text {th }}$ supporting

DC

M A large positive number

Decision variables

$B B_{p a} \quad$ The amount of the $a^{\text {th }}$ product made by the $p^{\text {th }}$ manufacturer, and bought by the $D C \mathrm{~s}$

$B_{\text {pia }} \quad$ The amount of the $a^{\text {th }}$ product sent from the $p^{\text {th }}$ manufacturer to the $i^{\text {th }} D C$

$p d c s r_{j a} \quad$ The sales price of the $a^{\text {th }}$ recyclable product returned by the $j^{\text {th }}$ customer to a $D C$

$R A_{j i a} \quad$ The amount of the $a^{\text {th }}$ product returned by the $j^{\text {th }}$ customer to the $i^{\text {th }} D C$ for remanufacturing

$R B_{j i a} \quad$ The amount of the $a^{\text {th }}$ product returned by the $j^{\text {th }}$ customer to the $i^{\text {th }} D C$ for repairing 
$R C_{j i a} \quad$ The amount of the $a^{\text {th }}$ product returned by the $j^{\text {th }}$ customer to the $i^{\text {th }} D C$ for recycling in the secondary chain

$Q A_{i a} \quad$ The total number of the $a^{\text {th }}$ product returned to the $i^{\text {th }} D C$ for remanufacturing

$Q B_{i a} \quad$ The total number of the $a^{\text {th }}$ product returned to the $i^{\text {th }} D C$ for repairing

$Q C_{i a} \quad$ The total number of the $a^{\text {th }}$ product returned to the $i^{\text {th }} D C$ to be recycled in the secondary chain

$q A_{i p a} \quad$ The amount of the $a^{\text {th }}$ product shipped from the $i^{\text {th }} D C$ to the $p^{\text {th }}$ manufacturer for remanufacturing

$x_{p} \quad$ Binary variable deciding whether or not to open the $p^{\text {th }}$ manufacturing facility

$y_{i}^{U} \quad$ Binary variable deciding whether or not to establish the $i^{\text {th }} D C$ with disruption

$y_{i}^{R} \quad$ Binary variable deciding whether or not to establish the $i^{\text {th }} D C$ without disruption

$T_{i j a}^{P} \quad 1$, if the primary allocation to satisfy the demands for the $a^{\text {th }}$ product by the $j^{\text {th }}$ customer is through the $i^{\text {th }} D C$, and 0 otherwise

$T_{i j a}^{B} \quad 1$, if the supporting allocation to satisfy the demands for the $a^{\text {th }}$ product by the $j^{\text {th }}$ customer is through the $i^{\text {th }} D C$, and 0 otherwise

$T_{i j a}^{S} \quad 1$, if the primary and supporting allocations to satisfy the demands for the $a^{\text {th }}$ product by the $j^{\text {th }}$ customer is through the $i^{\text {th }} D C$ simultaneously, and 0 otherwise

$A_{j a} \quad 1$, if the $a^{\text {th }}$ product returned by the $j^{\text {th }}$ customer is remanufactured, and 0 otherwise

$B_{j a} \quad 1$, if the $a^{\text {th }}$ product returned by the $j^{\text {th }}$ customer is repaired, and 0 otherwise 
$C_{j a} \quad 1$, if the $a^{\text {th }}$ product returned by the $j^{\text {th }}$ customer is sent to be recycled in the secondary chain, and 0 otherwise

\subsection{Problem Formulation}

The main objective function in Eq. (1) maximizes the profit of the manufacturers $\left(Z_{1}\right)$, the $D C$ s $\left(Z_{2}\right)$, and the customers $\left(Z_{3}\right)$, simultaneously. The first objective function (Eq. 2) is calculated by the difference of the production profit, and the cost of remanufacturing, facility establishment, and the cost of transportation from the manufacturer to the $D C$ s. The second objective in Eq. (3) measures the $D C$ s' final profit by calculating thirteen separate statements as follows: the revenue gained by the $D C$ s from selling the original products to the customer, plus the $D C$ s' profit by selling the returns under warranty to the manufacturer for remanufacturing, plus the sale profit of sending the recyclable items to the secondary chain, plus the profit from repairing the returned products, minus the cost of purchasing the products from the manufacturers, minus the cost of buying the recyclable returns from the customer, minus the fixed costs of establishing the primary and supporting $D C$ s, and transportation costs from the primary and supporting $D C$ s to the customer and vice versa, while extracting the overlap in simultaneous allocations. The third objective in Eq. 4 calculates the customers' profit by measuring the sum of the revenue from selling the recyclable products to the $D C$ s, plus the profit from reworking the products by the customers, minus the cost of purchasing the products from the $D C \mathrm{~s}$, minus the repair cost of an item, payable to the $D C$ s.

$$
\begin{aligned}
& y=\max \left(Z_{1}, Z_{2}, Z_{3}\right) \\
& Z_{1}=\sum_{p} \sum_{a}\left(p f_{p a}-C_{p a}\right) B B_{p a}-\sum_{p} \sum_{a} \sum_{i} p s_{p a} q A_{i p a}-\sum_{p} x_{p} C o_{p}-\sum_{p} \sum_{i} \sum_{a} h_{p i a} B_{p i a}
\end{aligned}
$$




$$
\begin{aligned}
& Z_{2}=\sum_{i} \sum_{j} \sum_{a} p d f_{j a} D_{j a}\left(T_{i j a}^{P}+T_{i j a}^{B}-T_{i j a}^{S}\right)+\sum_{i} \sum_{p} \sum_{a} g b_{i p a} \times q A_{i p a}+ \\
& \sum_{i} \sum_{a}\left(g c_{i a}-\text { pnsc }_{i a}\right) Q C_{i a}+\sum_{i} \sum_{a}\left(g a_{i a}-\text { prep }_{i a}\right) Q B_{i a}-\sum_{p} \sum_{a} B B_{p a} p f_{p a}- \\
& \sum_{j} \sum_{a} \sum_{i} p d c s r_{j a} \alpha_{j a} D_{j a}\left(T_{i j a}^{P}+T_{i j a}^{B}-T_{i j a}^{S}\right)-\left(\sum_{i} y_{i}^{U} f_{i}^{U}+\sum_{i} y_{i}^{R} f_{i}^{R}\right)- \\
& \sum_{i} \sum_{j} \sum_{a}\left(1-p o_{i}\right) D_{j a} h_{i j a}^{P} T_{i j a}^{P}-\sum_{i} \sum_{j} \sum_{a} p o_{i} D_{j a} h_{i j a}^{B} T_{i j a}^{B}- \\
& \sum_{i} \sum_{j} \sum_{a}\left(1-p o_{i}\right) \alpha_{j a} D_{j a} h e_{j i a}^{P} T_{i j a}^{P}-\sum_{i} \sum_{j} \sum_{a} p o_{i} \alpha_{j a} D_{j a} h e_{j i a}^{B} T_{i j a}^{B}+ \\
& \sum_{i} \sum_{j} \sum_{a} p o_{i} D_{j a}\left(h_{i j a}^{B}-h_{i j a}^{P}\right) T_{i j a}^{S}+\sum_{i} \sum_{j} \sum_{a} p o_{i} \alpha_{j a} D_{j a}\left(h e_{i j a}^{B}-h e_{i j a}^{P}\right) T_{i j a}^{S} \\
& Z_{3}=\sum_{i} \sum_{j} \sum_{a} p d c s r_{j a} \alpha_{j a} D_{j a}\left(T_{i j a}^{P}+T_{i j a}^{B}-T_{i j a}^{S}\right)+ \\
& \sum_{i} \sum_{j} \sum_{a}\left(t f_{j a}-e f_{j a}\right) \times \beta_{j a} D_{j a} \times\left(T_{i j a}^{P}+T_{i j a}^{B}-T_{i j a}^{S}\right)- \\
& \sum_{i} \sum_{j} \sum_{a} p d f_{j a} D_{j a} \times\left(T_{i j a}^{P}+T_{i j a}^{B}-T_{i j a}^{S}\right)-\sum_{i} \sum_{a} g a_{i a} Q B_{i a} \\
& B B_{p a}=\sum_{i} B_{p i a} \quad \forall p \in P, a \in A \\
& \sum_{p} \sum_{i} B_{p i a}+\sum_{i}\left(Q B_{i a}+Q A_{i a}\right)=\sum_{j} \sum_{i} D_{j a} *\left(T_{i j a}^{P}+T_{i j a}^{B}-T_{i j a}^{S}\right) \quad \forall a \in A \\
& \sum_{i} \alpha_{j a} D_{j a}\left(T_{i j a}^{P}+T_{i j a}^{B}-T_{i j a}^{S}\right)=\sum_{i}\left(R A_{j i a}+R B_{j i a}+R C_{j i a}\right) \quad \forall j \in J, a \in A \\
& \sum_{i} T_{i j a}^{P}=1, \sum_{i} T_{i j a}^{B}=1 \quad \forall j \in J, a \in A \\
& T_{i j a}^{S} \leq T_{i j a}^{P}, T_{i j a}^{S} \leq T_{i j a}^{B} \quad \forall i \in I, j \in J, a \in A \\
& T_{i j a}^{P} \leq\left(y_{i}^{U}+y_{i}^{R}\right), T_{i j a}^{B} \leq y_{i}^{R} \quad \forall i \in I, j \in J, a \in A \\
& \left(y_{i}^{U}+y_{i}^{R}\right) \leq 1 \quad \forall i \in I
\end{aligned}
$$




$$
\sum_{i} y_{i}^{R} \geq 1
$$

$$
\left\{\begin{array}{l}
\text { if }\left(q_{j a} \geq \text { qrem }_{a}\right) \rightarrow\left(A_{j a}=1, p d c s r_{j a}=0\right) \\
\text { if }\left(\text { qrem }_{a} \geq q_{j a} \geq q r e p_{a}\right) \rightarrow\left(B_{j a}=1, p d c s r_{j a}=0\right) \\
\text { if }\left(q_{j a} \leq \text { qrep }_{a}\right) \rightarrow\left(C_{j a}=1, p d c s r_{j a}=0.5 \times p d f_{j a}\right)
\end{array}\right.
$$

$Q A_{i a}=\sum_{j} R A_{j i a}$

$\forall i \in I, a \in A$

$$
Q B_{i a}=\sum_{j} R B_{j i a}
$$

$$
Q C_{i a}=\sum_{j} R C_{j i a}
$$

$$
\sum_{j} R A_{j i a}=\sum_{p} q A_{i p a}
$$

$$
\sum_{j} D_{j a} * \alpha_{j a} * A_{j a} *\left(T_{i j a}^{P}+T_{i j a}^{B}-T_{i j a}^{S}\right)=Q A_{i a}
$$

$\sum_{j} D_{j a} * \alpha_{j a} * B_{j a} *\left(T_{i j a}^{P}+T_{i j a}^{B}-T_{i j a}^{S}\right)=Q B_{i a}$

$\sum_{j} D_{j a} * \alpha_{j a} * C_{j a} *\left(T_{i j a}^{P}+T_{i j a}^{B}-T_{i j a}^{S}\right)=Q C_{i a}$

$\forall i \in I, a \in A$

$y_{i}^{U} \leq \sum_{p} \sum_{a} B_{p i a}, y_{i}^{R} \leq \sum_{p} \sum_{a} B_{p i a}$

$\forall i \in I$

$$
\sum_{i} \sum_{a} B_{p i a} \leq M * x_{p}, \sum_{a} B B_{p a} \leq M * x_{p}
$$

$\forall p \in P$ 


$$
\left\{\begin{array}{l}
y_{i}^{U}, y_{i}^{R}, x_{p}, C_{j a}, B_{j a}, A_{j a}, T_{i j a}^{S}, T_{i j a}^{B}, T_{i j a}^{P} \in\{0,1\} \\
q A_{i p a}, Q C_{i a}, Q B_{i a}, Q A_{i a}, R A_{j i a}, R B_{j i a}, R C_{j i a}, B_{p i a}, B B_{p a}, M \in \mathrm{Z}^{+} \\
p d c s r_{j a} \geq 0
\end{array}\right.
$$

Constraint (5) ensures that all the manufactured products are sent to the DCs. Constraint (6) indicates that the sum of original, repaired and remanufactured products of a certain type sent to the $D C$ s should be equal to the customers' demand for that type of product. Constraint (7) indicates that the returns sent back to the $D C$ s should be either remanufactured, repaired, or recycled. Constraint (8) ensures that each customer is assigned only to one primary $D C$ and/or one supporting $D C$. Constraint (9) considers an overlap situation when one customer is simultaneously assigned to the same $D C$ in both primary and supporting allocations. Constraint (10) states that in the primary allocation, a customer can be assigned to any $D C$ with(out) disruption, while in the supporting allocation, customers may only be assigned to a $D C$ without disruption. Constraint (11) ensures that only one $D C$ with or without disruption is established in any candidate site. Constraint (12) ensures that at least one $D C$ without disruption is built to handle the supporting allocations.

Constraint (13) sorts the returned items based on their qualities. The first statement ensures that the high-quality returns, covered by the warranty contract, are sent for remanufacturing. The second condition states that if the quality of the returned product is lower than the prerequisite for remanufacturing (i.e., the warranty is void), but higher than the required quality for repairing, then it is sent for repair. Otherwise, if the quality is lower than the requirements for remanufacturing or repairing, it is labelled as recyclable items and shipped to another chain. Moreover, the sale price of recyclable items is set to half the price of the original products. For simplicity, this non-linear equation can be linearized via the well-known, if-then conversion method [23]. 
Constraints (14) to (16) calculate the total number of products sent to the $D C$ s for remanufacturing, repairing, and recycling, respectively. Constraints (17) ensures that all the products with valid warranty returned by the customer are sent to the manufacturer via the $D C$ s. In the backward chain, constraints (18) to (20) respectively ensure that the collected items for remanufacturing, repairing, and recycling are sent to their corresponding centers/chain. Constraint (21) ensures that a $D C$, with/out disruption is opened to receive the products from the manufacturers. Constraint (22) sets a maximum capacity for the manufacturers' productions and the amount of cargo shipped to the DCs. Constraint (23) shows the range of the decision variables.

\section{Solution approach}

The Reservation level driven Tchebycheff procedure (RLTP) method covers all types of multiple objective problems and is often used to tackle mixed-integer and nonlinear models or bounded, nonconvex decision space. This approach is a weighting vector space reduction approach, based on the rationale that by sampling a weighted sequence of progressively smaller numbers of nondominated solutions in each iteration, a final solution (or a near-optimal solution) will be found to satisfy the decision-maker [24]. Due to the repeated sampling process, the algorithm is proved to have a multiple starting point property, which prevents it from getting trapped in the local optima [25]. For a typical multi-objective maximization problem with $F$ objectives, i.e., $\max \left\{f_{k}(x) ; x \in X\right\} ; \forall k=1, \ldots, F$, this method can be explained as follows:

Step 1- Parameters setting and reference vectors

1.1. Determine the number of non-dominated solutions $(N)$ to be presented to the decision-maker per stage $(N \geq F)$.

1.2. Calculate the reference objective vector $\left(y^{* *}\right)$ as follows: 


$$
\begin{aligned}
& y^{* * *}=\left(y_{1}^{* *}, y_{2}^{* *}, \ldots, y_{F}^{* *}\right), \\
& y_{k}^{* * *}=\max \left\{f_{k}(x) ; x \in X\right\}+\varepsilon_{k} ; \forall k=1: F
\end{aligned}
$$

where $\varepsilon_{k} ; \forall k=1: F$ are moderately small, computationally significant, positive values [25].

1.3. Set the initial value for the Reservation Level of the $k^{\text {th }}$ objective $\left(R L_{k}=-\infty ; \forall k=1: F\right)$.

1.4. Set the value for the reduction factor $r \in(0,1)$, where the smaller values shrink the objective region more rapidly.

1.5. Specify the number of required iterations.

Step 2- Weight generation

Generate at least $2 N$ randomly generated and widely dispersed $\lambda$-vectors via Eq. (25):

$$
\Lambda=\left\{\lambda \in R^{F} \mid \lambda_{k} \in(0,1), \sum_{k=1}^{F} \lambda_{k}=1\right\} .
$$

\section{Step 3- Optimization}

Solve the problem in Eqs. (26)-(29) for each $\lambda$-vector calculated in step 2, where $\rho$ is a sufficiently small, numerically significant, positive scalar within the recommended range of $\rho \in(0.0001-0.01)$

$$
\min \left\{\alpha-\rho \sum_{k=1}^{F} f_{k}(x)\right\}
$$

s.t.

$x \in X$ 


$$
\begin{array}{ll}
\alpha \geq \lambda_{k}\left(y_{k}^{* *}-f_{k}(x)\right) \geq 0 & \forall k=1, \ldots, F \\
f_{k}(x) \geq R L_{k} & \forall k=1, \ldots, F
\end{array}
$$

Next, from the resultant solution set, the $N$ number of most diverse solutions are selected and presented to the decision-maker. If the decision-maker is satisfied with the results, the procedure is stopped; otherwise, the algorithm proceeds to the next stage.

\section{Step 4- Adjustment}

This step is a more interactive stage, where the decision-maker is asked to divide the solutions into two categories of "most preferred" and "least preferred". Values for the $R L_{k} ; \forall k=1, \ldots, F$ are adjusted according to the decision-maker's opinion, or based on Eq. (30) proposed by Reeves \& Macleod [26], where $C S W V_{K}$ is the worst value in the set of all the current solutions, and $M P W V_{K}$ is the worst value in the most preferred subset of solutions.

$$
R L_{k}=M P W V_{k}+r\left(M P W V_{k}-C S W V_{k}\right)
$$

After adjusting the $R L_{k}$, the algorithm returns to step 2 .

\section{Model validation}

In this section, the RLTP method is applied to the proposed model in section 2 via a numerical example. In this case, two manufacturers (i.e., $P=2$ ) ship the products to two $D C$ s (i.e., $I=2$ ), where the demands from two types of products (i.e., $A=2$ ) are received from three customer markets (i.e., $J=3$ ). Moreover, the disruption probability is randomly drawn from a uniform 
distribution ( $0-1)$, and is set as $p o_{1}=0.6, p o_{2}=0$, and let $M=100000000$. Other values for the initial parameters are borrowed from a CLSCN by Masoudipour [8], and summarized in Table 1. For the relation between the parameters and an extensive sensitivity analysis, the interested reader is referred to the aforementioned paper. The experiments in this paper are executed via the IBM CPLEX Studio software on a $P C$ with the following configurations: CPU Core i7, Windows 10, and 8 GB of RAM.

In the first step, for the three objectives of the problem, it is decided to present three solutions to the decision-maker per iteration $(F=N=3)$. The reference objective vectors are calculated and shown in Table 2, where the maximum solution per objective is indicated by bold values. The reduction factor $r$ is set to 0.0001 , and let $R L_{k}=-\infty ; \forall k=1: 3, \varepsilon_{k}=0.0001 ; \forall k=1: 3$.

In the second stage, six distinct weight vectors were randomly generated via Eq. (25), and summarized in the first consecutive rows of Table 3. In the third step, the corresponding RLTP model was solved for the six $\lambda$-vectors considering $\rho=0.0001$ and the objective values per vector are depicted in the third to sixth rows of Table 3. The final row of Table 3 shows the corresponding objective value of Eq. (26) for each vector.

In this instance, the decision-maker is not satisfied with the results, and defines a most preferred subset solutions as $\{2,1\}$, and a least preferred subset as $\{3,4,5,6\}$.

Thus, the $R L_{k} ; \forall k=1,2,3$ are adjusted for the next iteration as follows, and the algorithm returns to step 3:

$$
\begin{aligned}
& R L_{1}=86457+(0.0001 *(86457-56176.99))=86460.03 \\
& R L_{2}=165155+(0.0001 *(165155-75417))=165164 \\
& R L_{3}=-459240+(0.0001 *(-459240+459240))=-459240
\end{aligned}
$$


Table 4 summarizes the results of the second and third iterations. It can be seen that in iteration 2 , the objective values for solutions $1,3,4,5$, and 6 are similar, while their corresponding $R L T P$ objectives are different. This is due to different $\alpha$ values in Eq. (28) that are resulted from variable $\lambda$-vectors. Such results show the efficiency of the RLTP method, since the algorithm is trapped in a local-optima, while a shift in the $\lambda$-vectors in solution 2 can move the searching area to other promising regions.

Updating the $R L_{k} ; \forall k=1,2,3$ for the third iteration with the most preferred subset solutions set as $\{2\}$, and least preferred subset as $\{1,3,4,5,6\}$ leads to $R L_{1}=101258.11, R L_{2}=173895.28$, and $R L_{3}=-455883.09$. The model returns the "No solution" warning, and the algorithm is terminated, returning solutions 1 and 2 as the two non-dominated solutions of the numerical example. This heuristic can be easily applied to larger scale problems where the opinion of the decision-maker directs the progress of the algorithm and sets its termination point.

Next, for the same numerical example, the performance of RLTP method is tested against the augmented $\varepsilon$-constraint algorithm [27], which has a similar structure in finding the non-dominated values by iteratively restricting the searching area. Three well-known performance metrics are used for comparison [28]; the overall non-dominated vector generation $(O N V G)$, the normalized maximum spread $(M S)$, and the mean ideal distance $(M I D)$. The $O N V G$ counts the number of nondominated solutions obtained from an algorithm, ergo, higher values of $O N V G$ are desirable. The normalized $M S$ indicates the distance between the non-dominated solutions in the obtained Pareto front. Thus, values near 1 for $M S$ shows a better exploration of an algorithm. The MID metric is an indicator of closeness between the achieved Pareto solutions and the ideal point per objective, 
hence, lower values of MID are preferrable. Table 5 summarizes the comparison results between the two algorithms.

As can be seen in Table 5, the $\varepsilon$-constraint method finds more non-dominated solutions than RLTP. However, the diversity of the non-dominated solutions found by RLTP is better as indicated by a higher value of $M S$. Moreover, the convergence and the quality of the solutions found by RLTP are preferrable as depicted by lower values of MID.

\section{Experiments and Results}

This section investigates the effects of key parameters on the objective values. The first group of parameters point out to the segmentation policy for remanufacturing, repairing and recycling, corresponding to the parameters $q_{r e m}$ and qrep $_{a}$ in the model presented in section 2 . The second parameter is the disruption probability, $p o_{i}$, which has been tested to analyze its effect on the locations, allocations and overall profits. The remaining parameters are similar to the first example in section 4. For simplicity, the $\lambda$-vectors in Table 4 are applied to all the instances.

\subsection{Testing the quality of the returned products}

In the backward flow, the quality of returns is a deciding factor in the segmentation process, which in turn affects the prices/costs and ultimately the profits of each entity in the chain. For instance, to examine the quality-profit relationship in the model, it is assumed that the quality of each return is lower than $100 \%$, and falls in the range of $[0,90]$. The defined range of quality for remanufacturing, repairing, and recycling are set at [70,90], [50,70), and [0,50), respectively. For instance, a return with $25 \%$ of quality in comparison to the original product is shipped to another chain for recycling, an item with $60 \%$ of quality is sent for repair, and a product with $85 \%$ of 
quality is covered by the warranty agreement and is fit for remanufacturing. For simplicity, it is assumed that at a specific point in time, the quality of all the returned items is similar. The model is solved for all the three ranges of quality, and the nondominated solutions are provided in Table 6 , where the quality range $[0,50)$ returns four nondominated solutions, while ranges $[50,70)$ and $[70,90]$ each find two solutions per objective. Furthermore, Fig. 2 depicts the return quality versus the gained profit for each entity of the $C L S C N$. According to Fig. 2, and Table 6, the $D C$ s profit the most in the quality range $[50,70)$ when they can increase their income by selling the repaired items to the customers for higher prices than the repairing costs. Another source of profit is available to the $D C$ s in the range $[70,90]$ when the $D C$ s collect the high-quality products covered by the warranty and sell them to the manufacturers. However, once the quality decreases to the range $[0,50)$, the $D C$ s receive lower profits since the recyclable items are sold to the secondary chain for half their actual prices.

The main revenue for the manufacturer is by selling the original products to the $D C \mathrm{~s}$ in the forward flow, and ergo its profit is almost constant except for the price paid to the $D C$ s for collecting the products covered by the warranty agreement in the range $[70,90]$.

The only revenue for the customer is through selling the low-quality items in the range $[0,50)$ to the secondary chains via the $D C$ s, and ergo the customer profits the most by simply returning the end-of-life products. The lowest profit for this group is in the range $[50,70)$ when the customer compensates the $D C$ s for repairing the item. The warranty coverage in the range $[70,90]$ reduces the costs inflicted on the customers and increases their profits.

Overall, it can be deducted that in such a $C L S C N$, returns with medium-range quality $[50,70)$ are preferred by the $D C$ s and the manufacturers, while due to the incentives offered by the $D C$ s for recyclable items, the customer prefers the low-quality returns. The highest average profit of the 
entire chain (equal to 305722.67 ) is achieved in the range $\left[50,70\right.$ ) for objective values $z_{1}=83617$ ,$z_{2}=267575$ and $z_{3}=-512280$ depicted in Table 6.

\subsection{Testing on the probability of disruption}

In the forward flow, candidate sites are dedicated to open primary and/or supporting $D C$ s considering the probability of disruption (i.e., $p o_{i} ; \forall i \in I$ ). By default, opening a primary $D C$ is

less expensive and more cost-effective (i.e., $f_{i}^{R}>f_{i}^{U}$ ), while establishing at least one supporting $D C$ without the possibility of disruption is essential to ensure an uninterrupted flow of service, and the availability of a $D C$ at all times. The two $D C$ s are considered similar in all aspects (except for the probability of disruptions), and ergo, the analysis of an instance with $p o_{1}=0, p o_{2}=1$ can be interchangeably extended to the probabilities of $p o_{1}=1, p o_{2}=0$. In the following experiments, the values for $p o_{1}$ is progressively increased from 0 to 1 (with the steps of 0.2 ), while the second $D C$ is considered unavailable at all times (i.e., $p o_{2}=0$ ). Table 7 summarizes the average values of all the non-dominated solutions (NDS) found for different sets of disruptions. It should be noted that to ensure valid results from Eq. (3), at least one of the $D C$ s should face disruption ( $\left.p o_{1}>0\right)$. The first row in table 7 indicates the number of non-dominated solutions found per test for a specific set of probability disruption. The average values per objective for the achieved solutions are depicted in rows 2 to 4 . The mean value for each test in row 5 combines the three objectives with a similar weight (i.e., 1/3), and is used to showcase a trend in the data. This variable indicates that increasing the value of $p o_{1}$ (i.e., decreasing the probability of disruption $1-p o_{1}$ ) improves the overall performance of the chain (highlighted by bold values in row 5). The decisions related 
to opening a $D C$ with/out the risk of disruption (primary or supporting $D C$ ) are summarized in rows 6 to 9 . As can be seen in row 6 , and 8 , by the decrease in disruption probability for the first $D C$ (increase in the value of $p o_{1}$ ), the model prefers to construct a primary $D C$ (on average, $84 \%$ to $100 \%$ of the times) rather than a supporting $D C$ (on average $0 \%$ to $0.16 \%$ of the times), so as to minimize the facility establishment costs, and improve the $D C$ s' $^{\prime}$ profit. Similarly, in rows 7 and 9, the second $D C$ may disrupt with the probability of 1 , thus, this facility is always established as a supporting $D C$ as depicted by the values of $y_{2}^{R}=1$ for all the instances.

Rows 10 and 11 indicate the decisions on the opening of manufacturing facilities. Since the two manufacturers are considered similar, the model balances the workload between them based on the probability of disruption, and ensures that at least one manufacturing site is always opened. Thus, the cumulative values of $x_{1}$ and $x_{2}$ for all instances are equal to $1\left(x_{1}+x_{2}=1\right)$.

For further analysis, for a mid-range set of disruption probability $p o_{1}=0.6, p o_{2}=0$, the optimal limits for a single objective (maximum and minimum values) are found in table 8 . The first two rows in table 8 shows that if only the profit of the manufacturer was to be considered, the manufacturers gain the most by opening one manufacturing site, one primary $D C$ and a supporting $D C$. However, once a second manufacturing facility is added, and both $D C$ are built as supporting $D C$ s, the manufacturers' profit reduces to its lowest. This can be explained based on the additional cost of establishing a manufacturing facility, and the fact that the manufacturer has to cover more remanufacturing demands by the establishment of two supporting $D C$ s (rather than one primary and one supporting $D C$ s). The $D C$ s profit the most once both manufacturers are operating, as the $D C$ s can increase their gain by selling more original products. Moreover, the profit of the $D C$ s 
plumps as more supporting $D C$ s are constructed, since they cost higher than their primary counterparts.

The customer prefers lower numbers of established $D C$ s to minimize the transportation costs, while he remains indifferent to the opening of either manufacturing site as long as at least one (or both) facility covers the remanufacturing processes.

\section{Managerial Insights}

- A closed-loop supply chain leads to the collection and re-usage of the residual value of returned products, and depending on the recovery options, it may create a zero-waste chain.

- In the forward and backward flows, appropriate location of facilities and allocation of customers result in higher profit, better responsiveness, and overall customer satisfaction.

- The policies regarding the segmentation of returned products should be defined based on their quality. Thus, the recovery route with the least cost and highest profit can be easily distinguished considering the quality of the returns.

- Once the returned items of the present chain are of so low a quality that cannot be used in any form, instead of regarding them as waste, they can be sold to the supply chain of another industry.

- Due to the weather conditions, floods, earthquakes, wars, staff strikes, changes in management hierarchy, legislation and government policies, machine breakdown or human error, any facility in a chain may be unavailable at one time. Thus, the possibility of disruption is a crucial factor to be considered in mathematical models.

- Considering the supporting distribution centers along with the primary ones ensures the constant availability of service even upon the occurrence of disruptions. 
- While satisfactory to the customer, a warranty period ought to be designed in a way that leads to the least cost for the manufacturer. If other words, the warranty period should be related to the quality reduction rate of a product.

\section{Conclusion}

The proposed tri-echelon CLSCN in this paper factors in the manufacturers, the distribution centers, and the customers, and considers four policies to handle the returned items: remanufacturing by the manufacturer according to the warranty contract, reworking by the choice of the customer, repairing by the $D C$, or recycling by selling the items to a secondary chain. The model is solved with RLTP method, and the tests on the quality segmentation reveal that the manufacturer gains the most profit by increasing the sale of original products in the forward flow. The $D C$ s profit the most in the medium-range quality by increasing their income via the sale of repaired items. Additionally, the customer can maximize his profit by selling the end-of-life products to the $D C$ s in the backward chain, and benefitting from the cost-reduction options of reworking and warranty agreements. The highest average profit of the entire chain is achieved in the medium-range quality, which can guide the managerial strategies on pricing decisions of the backward chain. The investigation on the probability of disruption depicts that with the reduction in the probability of disruption, the model prefers to open a primary $D C$ rather than a secondary $D C$, and also opens the minimum number of manufacturing and distributing sites to lower the cumulative costs, and improve the overall performance. Future studies on the subject can cover the addition of inventory decisions, and demand uncertainty to the model, and considering the disruption parameters as fuzzy or grey numbers. Finally, developing other heuristics based on stochastic programming or robust optimization to handle the disruptions can be a suitable avenue for more complex problems. 


\section{References}

1. Tordecilla, R.D. Juana, A.A. Montoya-Torres, J.R. Quintero-Araujo, C.L. Panadero, J. "Simulation-optimization methods for designing and assessing resilient supply chain networks under uncertainty scenarios: A Review", Simulation Modelling Practice and Theory, DOI: 10.1016/j.simpat.2020.102166 (2021).

2. Chowdhury, M.M.H, Quaddus, M.A. "Supply chain sustainability practices and governance for mitigating sustainability risk and improving market performance: A dynamic capability perspective", Journal of Cleaner Production, DOI: 10.1016/j.jclepro.2020.123521 (2021).

3. Tolooie, A., Maity, M., Sinha, A.K. “A two-stage stochastic mixed-integer program for reliable supply chain network design under uncertain disruptions and demand", Computers \& Industrial Engineering, DOI: 10.1016/j.cie.2020.106722 (2020).

4. Govindan, K., Soleimani, H. "A review of reverse logistics and closed-loop supply chains: a journal of cleaner production fFocus", Journal of Cleaner Production, 142(1), 371-384 (2017).

5. Bazan, E., Jaber, M. Y., Zanoni, S. "Carbon emissions and energy effects on a two-level manufacturer-retailer closed-loop supply chain model with remanufacturing subject to different coordination mechanisms", International Journal of Production Economics, 183(Part B), pp. 394-408 (2017).

6. Maiti, T., Giri, B. C. "Two-way product recovery in a closed-loop supply chain with variable markup under price and quality dependent demand", International Journal of Production Economics, 183(Part B), pp. 259-272 (2017).

7. Xu, Z., Pokharel, S., Elomri, A., Mutlu, F. "Emission policies and their analysis for the design of hybrid and dedicated closed-loop supply chains", Journal of Cleaner Production, 142(Part 4), pp. 4152-4168 (2017). 
8. Masoudipour, E., Amirian, H., Sahraeian, R. "A novel closed-loop supply chain based on the quality of returned products", Journal of Cleaner Production, 151(1), pp. 344-355 (2017).

9. Zhen, L., Huang, L., Wang, W. "Green and sustainable closed-loop supply chain network design under uncertainty”, Journal of Cleaner Production, 227(1), pp. 1195-1209 (2019).

10. Yi, P., Huang, M., Guo, L., Shi, T. “A Retailer Oriented Closed-loop Supply Chain Network Design for End-of-Life Construction Machinery Remanufacturing", Journal of Cleaner Production, 124(1), pp. 191-203 (2016).

11. Ahmadzadeh, E., Vahdani, B. "A location-inventory-pricing model in a closed loop supply chain network with correlated demands and shortages under a periodic review system", Computers \& Chemical Engineering, 101(1), pp. 148-166 (2017).

12. Mirmohammadi, S. H., Sahraeian, R. "A Novel Sustainable Closed-loop Supply Chain Network Design by Considering Routing and Quality of Products”, International Journal of Engineering-Transactions B: Applications, 31(11), pp. 1918-1928 (2018).

13. Yu, H., Solvang, W. D. “A fuzzy-stochastic multi-objective model for sustainable planning of a closed-loop supply chain considering mixed uncertainty and network flexibility", Journal of Cleaner Production. DOI: 10.1016/j.jclepro.2020.121702, (2020).

14. Govindan, K., Mina, H., Esmaeili, A., Gholami-Zanjani, S. M. “An integrated hybrid approach for circular supplier selection and closed loop supply chain network design under uncertainty", Journal of Cleaner Production, DOI: 0.1016/j.jclepro.2019.118317, (2020).

15. Ghomi-Avili, M., Jalali Naeini, S. G., Tavakkoli-Moghaddam, R., Jabbarzadeh, A. “A fuzzy pricing model for a green competitive closed-loop supply chain network design in the presence of disruptions", Journal of Cleaner Production. 188(1), pp. 425-442 (2018). 
16. Diabat, A., Jabbarzadeh, A., \& Khosrojerdi, A. (2019). “A perishable product supply chain network design problem with reliability and disruption considerations", International Journal of Production Economics, 212(1), pp. 125-138 (2018).

17. Huang, H., He, Y., Li, D. "Pricing and inventory decisions in the food supply chain with production disruption and controllable deterioration", Journal of Cleaner Production, 180(1), pp. 280-296 (2018).

18. Tong, L., Yang, K., Xu, W.J. “Optimal strategies for CLSC considering supply disruption and carbon tax", Mathematical Problems in Engineering, DOI: 10.1155/2020/9808370, (2020).

19. Darom, N. A., Hishamuddin, H., Ramli, R., Nopiah, Z. M. “An inventory model of supply chain disruption recovery with safety stock and carbon emission consideration", Journal of Cleaner Production, 197(1), pp. 1011-1021 (2018).

20. Shen, J. "An uncertain sustainable supply chain network," Applied Mathematics and Computation, DOI: 10.1016/j.amc.2020.125213, (2020).

21. Mohammadi, M. "Designing an integrated reliable model for stochastic lot-sizing and scheduling problem in hazardous materials supply chain under disruption and demand uncertainty”, Journal of Cleaner Production, DOI: 10.1016/j.jclepro.2020.122621, (2020).

22. Moshtagh, M. S., Taleizadeh, A. A. "Stochastic integrated manufacturing and remanufacturing model with shortage, rework and quality-based return rate in a closed loop supply chain", Journal of Cleaner Production, 141(1), pp. 1548-1573 (2017).

23. Chen, D.S., Batson, R.G., Dang, Y. “Applied integer programming: modeling and solution”, first ed., Wiley, (2010).

24. Demirtas, E.A., Üstün, Ö. “An integrated multi-objective decision making process for supplier selection and order allocation”, Omega, 26(1), pp. 76-90 (2008). 
25. Steuer, R. E., \& Choo, E. U. "An interactive weighted Tchebycheff procedure for multiple objective programming”, Mathematical Programming, 26(3), pp. 326-344 (1983).

26. Reeves, G.R., MacLeod, K.R. "Some experiments in Tchebycheff-based approaches for interactive multiple objective decision making", Computers and Operations Research, 26(1), pp. 1311-1321 (1999).

27. Bérubé, J., Gendreau, M., Potvin, J. "An exact $\varepsilon$-constraint method for bi-objective combinatorial optimization problems: Application to the traveling salesman problem with profits”, European Journal of Operational Research, 194(1), pp. 39-50 (2009).

28. Amirian, H., Sahraeian, R. "Augmented $\varepsilon$-constraint method in multi-objective flowshop problem with past sequence set-up times and a modified learning effect", International Journal of Production Research, 53(1), 5962-5976 (2015).

\section{Biographies}

Yasin Mansouri received his BSc in industrial engineering from the Islamic Azad University, Kermanshah Branch, Iran. He also received his MSc in industrial engineering from the Islamic Azad University, West Tehran Branch, Tehran. He is currently a Ph.D. Candidate at Shahed University, Tehran, Iran. His research interests include operations research and supply chain management.

Rashed Sahraeian is a Professor of Industrial Engineering at Shahed University. He holds a B.Sc. in Industrial Engineering from Amirkabir University of Technology, M.Sc., and Ph.D. from Tarbiat Modares University. His research interests include operations research, supply chain management, and scheduling. He has published some books and a large number of papers in recent years. 


\section{Figure and Table Captions}

Figure 1: An overview of the proposed CLSCN

Figure 2: Quality of returns versus the resultant profits

Table 1: Parameters of the numerical example

Table 2: The pay-off table of the numerical example

Table 3: RLTP solutions of the numerical example 1 in the first iteration

Table 4: RLTP solutions of the numerical example 1 in the second iteration

Table 5: Comparison between RLTP and $\varepsilon$-constraint algorithms for the numerical example 1

Table 6: Non-dominated solutions for different quality ranges

Table 7: Solutions for different probability of disruption

Table 8: Decisions on facility establishment for disruption probability (0.6-0) 


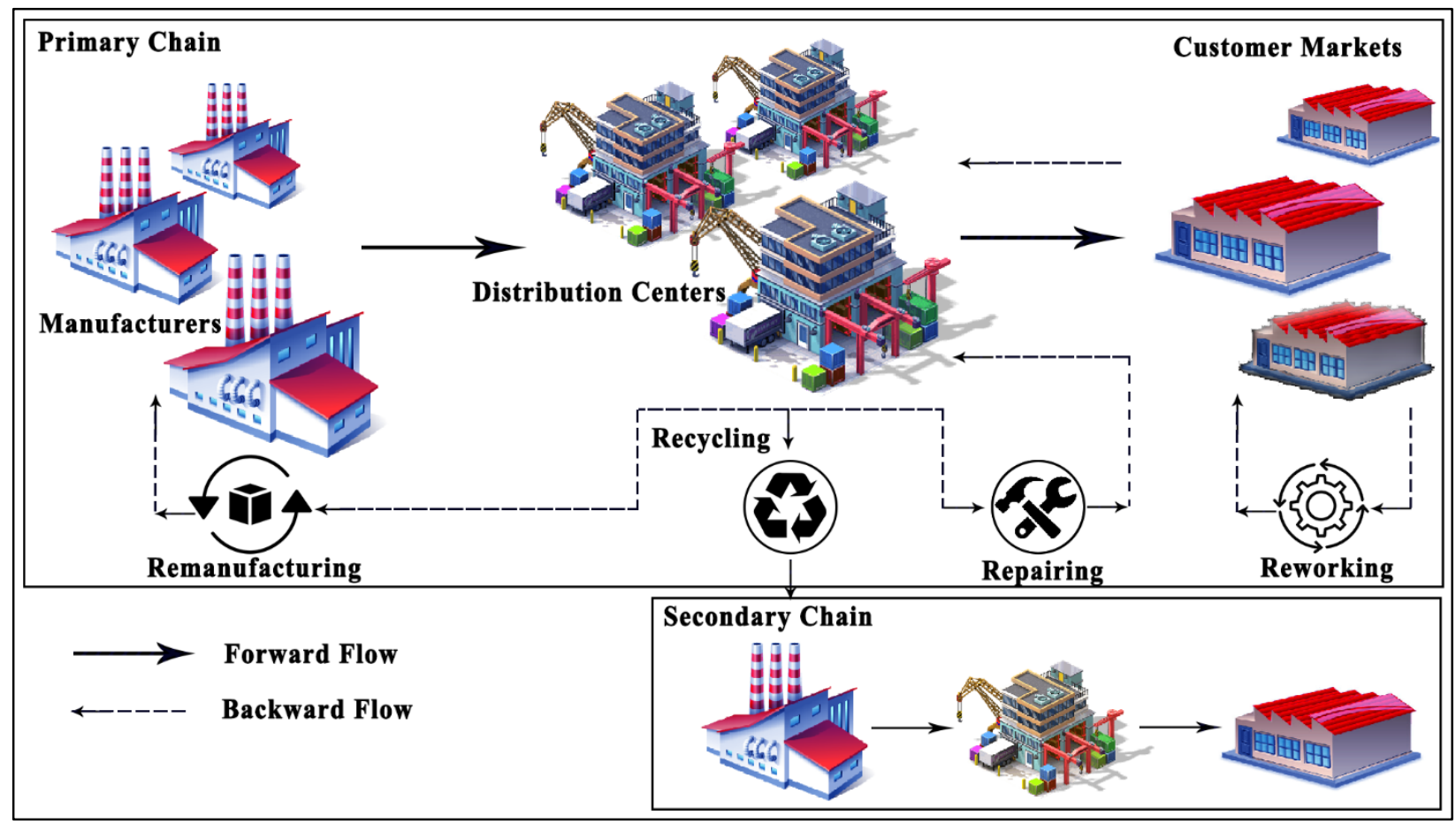

Figure 1: An overview of the proposed CLSCN 


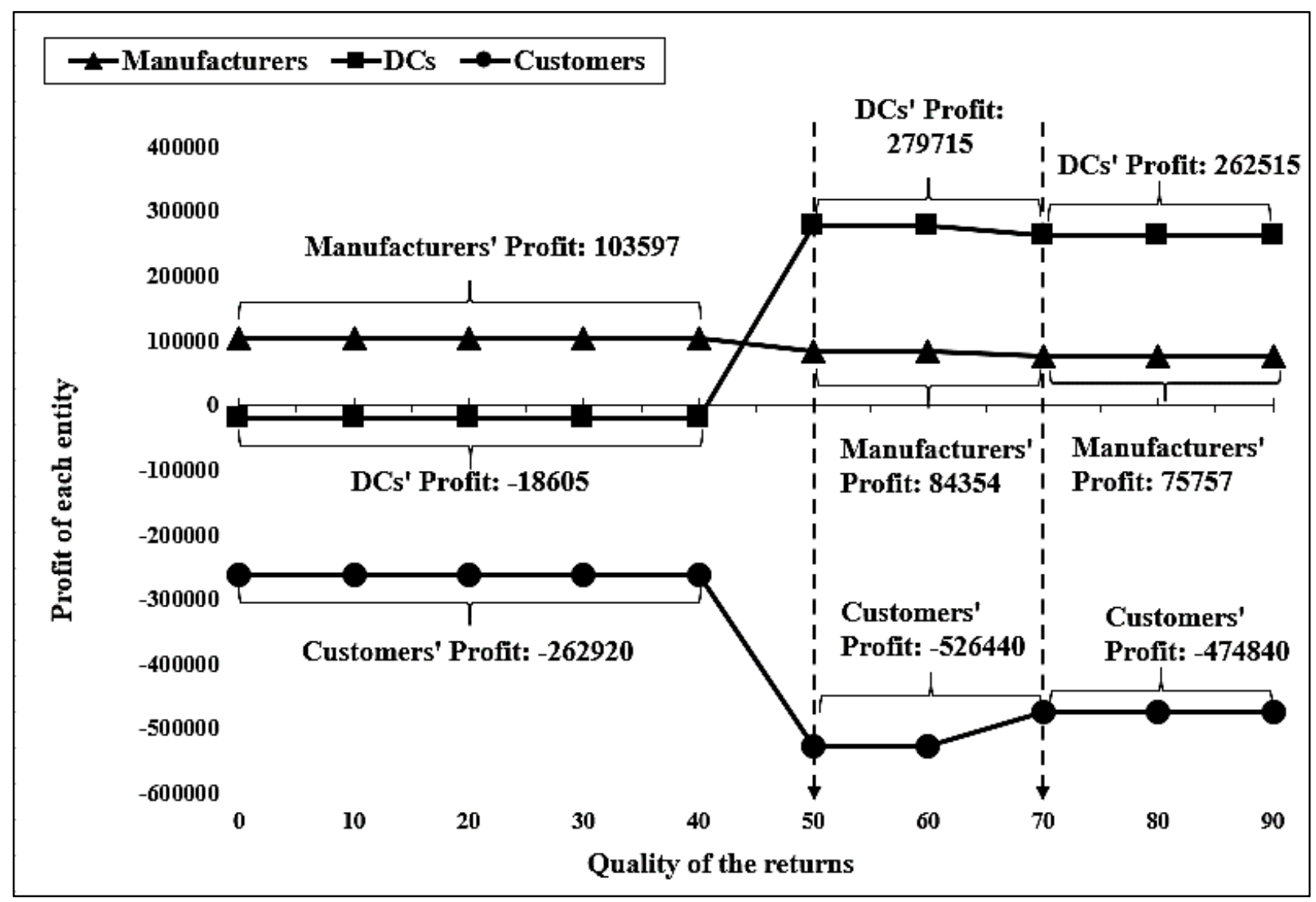

Figure 2: Quality of returns versus the resultant profits 
Table 1. Parameters of the numerical example

\begin{tabular}{|c|c|c|c|c|c|}
\hline Parameter & Value & Parameter & Value & Parameter & Value \\
\hline$D_{j a}$ & {$\left[\begin{array}{ll}200 & 200 \\
400 & 300 \\
600 & 400\end{array}\right]$} & $h_{\text {pia }}$ & {$\left[\begin{array}{l}{[[3,3][3,3]]} \\
{[[3,3][3,3]]}\end{array}\right]$} & qrep $_{a}$ & 50,50 \\
\hline$\alpha_{j a}$ & {$\left[\begin{array}{ll}0.2 & 0.2 \\
0.4 & 0.4 \\
0.6 & 0.4\end{array}\right]$} & $t f_{j a}$ & {$\left[\begin{array}{ll}10 & 10 \\
10 & 10 \\
10 & 10\end{array}\right]$} & qrem $_{a}$ & 70,70 \\
\hline$f_{i}^{R}=C o_{p}$ & {$\left[\begin{array}{ll}3 & 3\end{array}\right]$} & $p s_{p a}$ & {$\left[\begin{array}{ll}5 & 5 \\
5 & 5\end{array}\right]$} & $\beta_{j a}$ & {$\left[\begin{array}{ll}0.1 & 0.1 \\
0.2 & 0.2 \\
0.3 & 0.2\end{array}\right]$} \\
\hline$q_{j a}$ & {$\left[\begin{array}{ll}60 & 40 \\
40 & 20 \\
65 & 90\end{array}\right]$} & $C_{p a}$ & {$\left[\begin{array}{ll}60 & 60 \\
60 & 60\end{array}\right]$} & prep $_{i a}=g c_{i a}$ & {$\left[\begin{array}{ll}10 & 10 \\
10 & 10\end{array}\right]$} \\
\hline$p f_{p a}$ & {$\left[\begin{array}{ll}100 & 100 \\
100 & 100\end{array}\right]$} & $g a_{i a}$ & {$\left[\begin{array}{ll}30 & 30 \\
30 & 30\end{array}\right]$} & $p n s c_{i a}$ & {$\left[\begin{array}{ll}4 & 4 \\
4 & 4\end{array}\right]$} \\
\hline$p d f_{j a}$ & {$\left[\begin{array}{ll}120 & 120 \\
120 & 120 \\
120 & 120\end{array}\right]$} & $f_{i}^{U}$ & {$\left[\begin{array}{ll}2 & 2\end{array}\right]$} & $h_{i j a}^{P}=h_{i j a}^{B}$ & {$\left[\begin{array}{l}{[[5,5][5,5][5,5]]} \\
{[[5,5][5,5][5,5]]}\end{array}\right]$} \\
\hline$g b_{i p a}$ & {$\left[\begin{array}{l}{[[10,10][10,10]]} \\
{[[10,10][10,10]]}\end{array}\right]$} & $e f_{j a}$ & {$\left[\begin{array}{ll}4 & 4 \\
4 & 4 \\
4 & 4\end{array}\right]$} & $h e_{j i a}^{P}=h e_{j i a}^{B}$ & {$\left[\begin{array}{l}{[[5,5][5,5]]} \\
{[[5,5][5,5]]} \\
{[[5,5][5,5]]}\end{array}\right]$} \\
\hline
\end{tabular}


Table 2. The pay-off table of the numerical example

\begin{tabular}{cccc}
\hline Objectives & $Z_{1}$ & $Z_{2}$ & $Z_{3}$ \\
\hline$z_{1}$ & $\mathbf{1 1 2 3 5 7}$ & 112354 & 56174 \\
$z_{2}$ & 156795 & $\mathbf{1 7 4 6 7 5}$ & 75417 \\
$z_{3}$ & -484320 & -484320 & $\mathbf{- 2 4 2 1 6 0}$ \\
\hline
\end{tabular}

Table 3. RLTP solutions of the numerical example 1 in the first iteration

\begin{tabular}{ccccccc}
\hline Iteration 1 & 1 & 2 & 3 & 4 & 5 & 6 \\
\hline$\lambda_{1}$ & 0.03 & 0.90 & 0.35 & 0.05 & 0.45 & 0.33 \\
$\lambda_{2}$ & 0.95 & 0.07 & 0.55 & 0.05 & 0.10 & 0.33 \\
$\lambda_{3}$ & 0.02 & 0.03 & 0.10 & 0.90 & 0.45 & 0.34 \\
\hline$z_{1}$ & 86457 & 106437 & 73137 & 56176.99 & 70977 & 71657 \\
$z_{2}$ & 172854 & 165155 & 160775 & 75417.00 & 76455 & 105255 \\
$z_{3}$ & -417960 & -459240 & -371400 & -242160 & -280080 & -311160 \\
\hline$R L T P$ Obj & 3531.86 & 6531.16 & 13740.74 & 4973.95 & 18634.26 & 23473.42 \\
\hline
\end{tabular}


Table 4. RLTP solutions of the numerical example 1 in the second iteration

\begin{tabular}{ccccccc}
\hline Iteration 2 & 1 & 2 & 3 & 4 & 5 & 6 \\
\hline$\lambda_{1}$ & 0.025 & 0.90 & 0.35 & 0.03 & 0.15 & 0.33 \\
$\lambda_{2}$ & 0.94 & 0.04 & 0.40 & 0.01 & 0.40 & 0.33 \\
$\lambda_{3}$ & 0.035 & 0.06 & 0.25 & 0.96 & 0.45 & 0.34 \\
\hline$z_{1}$ & 90157 & 101257 & 90157 & 90157 & 90157 & 90157 \\
$z_{2}$ & 171075 & 173895 & 171075 & 171075 & 171075 & 171075 \\
$z_{3}$ & -424920 & -455880 & -424920 & -424920 & -424920 & -424920 \\
\hline$R L T P$ Obj & 6412.96 & 12841.27 & 45706.36 & 175465.96 & 82258.36 & 62154.76 \\
\hline
\end{tabular}

Table 5. Comparison between RLTP and $\varepsilon$-constraint algorithms for the numerical example 1

\begin{tabular}{ccc}
\hline Metric & $\varepsilon$-constraint & RLTP \\
\hline ONVG & 18 & 8 \\
$M S$ & 0.5649 & 0.8374 \\
MID & 424913.65 & 403910.05 \\
\hline
\end{tabular}


Table 6. Non-dominated solutions for different quality ranges

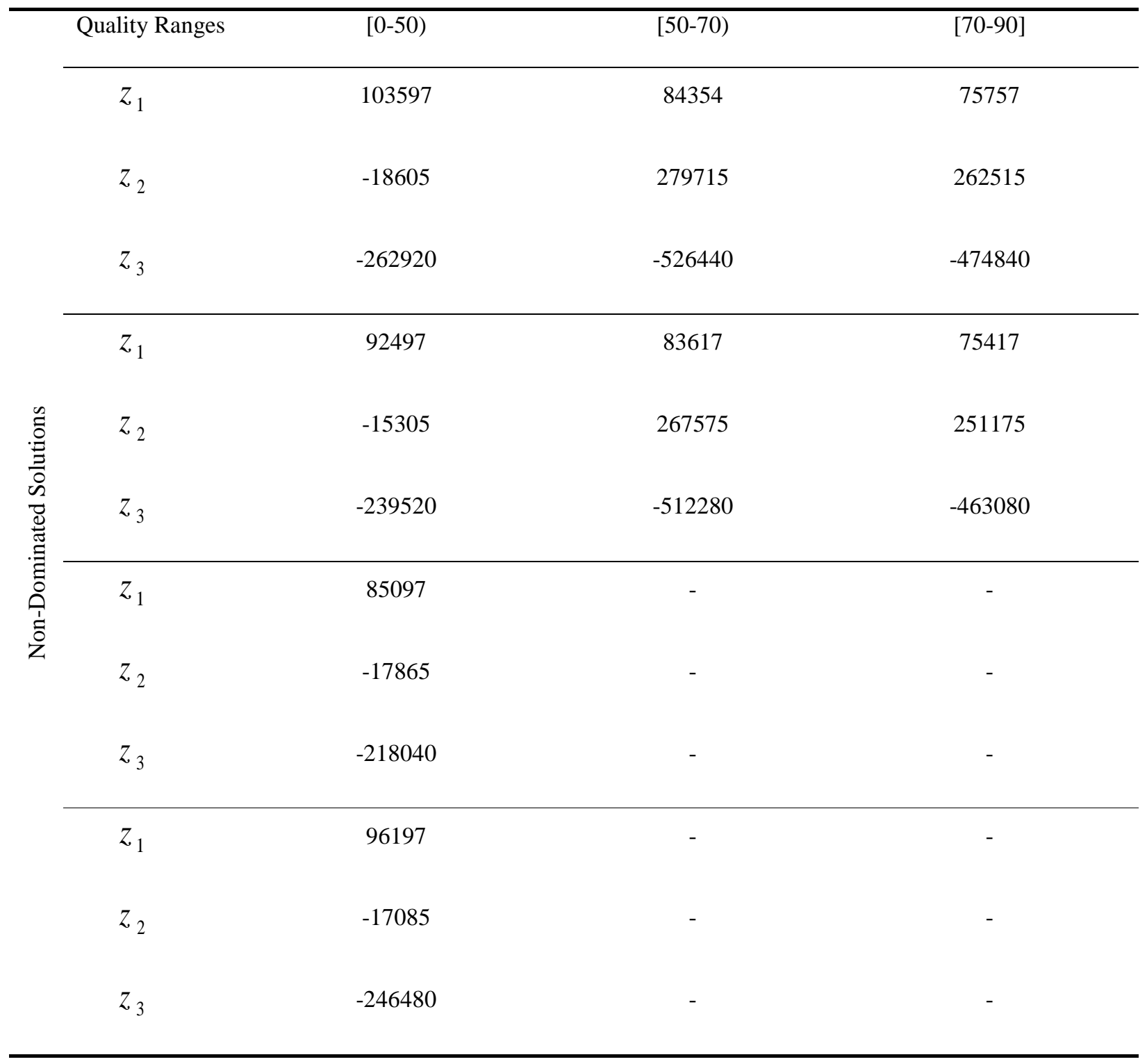


Table 7. Solutions for different probability of disruption

\begin{tabular}{lllllll}
\hline Row \# & {$\left[\mathrm{po}_{1}, \mathrm{po}_{2}\right]$} & {$[0.2,0]$} & {$[0.4,0]$} & {$[0.6,0]$} & {$[0.8,0]$} & {$[1,0]$} \\
\hline 1 & \# of $N D S$ & 19 & 19 & 21 & 21 & 21 \\
2 & $Z_{1}$ & 88621.21 & 89906.47 & 89683.67 & 89683.67 & 89683.67 \\
3 & $Z_{2}$ & 137315.89 & 136056.95 & 138186.24 & 140001.57 & 141816.90 \\
4 & $Z_{3}$ & -390423.16 & -390480.00 & -390200.00 & -390200.00 & -390200.00 \\
\hline 5 & Mean & $\mathbf{- 5 4 8 2 8 . 6 8}$ & $\mathbf{- 5 4 8 3 8 . 8 5}$ & $\mathbf{- 5 4 1 1 0 . 0 3}$ & $\mathbf{- 5 3 5 0 4 . 9 2}$ & $\mathbf{- 5 2 8 9 9 . 8 0}$ \\
\hline 6 & $y_{1}^{U}$ & 0.84 & 0.84 & 0.81 & 0.90 & 1.00 \\
7 & $y_{2}^{U}$ & $\mathbf{0 . 0 0}$ & $\mathbf{0 . 0 0}$ & $\mathbf{0 . 0 0}$ & $\mathbf{0 . 0 0}$ & $\mathbf{0 . 0 0}$ \\
8 & $y_{1}^{R}$ & 0.16 & 0.16 & 0.19 & 0.10 & 0.00 \\
9 & $y_{2}^{R}$ & $\mathbf{1 . 0 0}$ & $\mathbf{1 . 0 0}$ & $\mathbf{1 . 0 0}$ & $\mathbf{1 . 0 0}$ & $\mathbf{1 . 0 0}$ \\
\hline 10 & $x_{1}$ & 0.11 & 0.37 & 0.29 & 0.43 & 0.48 \\
\hline 11 & $x_{2}$ & 0.89 & 0.63 & 0.71 & 0.57 & 0.52 \\
\hline & & & & & &
\end{tabular}


Table 8. Decisions on facility establishment for disruption probability (0.6-0)

\begin{tabular}{|c|c|c|c|c|c|c|c|c|c|}
\hline \multirow{2}{*}{$\begin{array}{l}\text { Objectives } \\
\text { Trade-offs }\end{array}$} & \multicolumn{2}{|c|}{$\begin{array}{c}\text { Which } \\
\text { Manufacturer? }\end{array}$} & \multicolumn{2}{|c|}{$\begin{array}{c}\text { Open DC with } \\
\text { disruption? }\end{array}$} & \multicolumn{2}{|c|}{$\begin{array}{c}\text { Open DC without } \\
\text { disruption? }\end{array}$} & \multicolumn{3}{|c|}{ Non-dominated Solutions } \\
\hline & $x_{1}$ & $x_{2}$ & $y_{1}^{U}$ & $y_{2}^{U}$ & $y_{1}^{R}$ & $y_{2}^{R}$ & $z_{1}$ & $z_{2}$ & $z_{3}$ \\
\hline \multirow{2}{*}{$z_{1}$} & 0 & 1 & 1 & 0 & 0 & 1 & 112357 & 174675 & -484320 \\
\hline & 1 & 1 & 0 & 0 & 1 & 1 & 56174 & 75414 & -242160 \\
\hline $\max$ & 1 & 1 & 1 & 0 & 0 & 1 & 112354 & 174675 & -484320 \\
\hline $\min$ & 1 & 1 & 0 & 0 & 1 & 1 & 82074 & 71354 & -308520 \\
\hline \multirow{2}{*}{$z_{3} \quad$ min } & 1 & 1 & 0 & 0 & 0 & 1 & 56174 & 75417 & -242160 \\
\hline & 1 & 1 & 1 & 0 & 0 & 1 & 112354 & 174675 & -484320 \\
\hline
\end{tabular}

